\section{Release of CDC's 2016 Model Aquatic Health Code, Second Edition and Revised Hyperchlorination and Fecal Incident Response Recommendations}

The 2016 Model Aquatic Health Code (MAHC), Second Edition was released on July 15, 2016 (http://www.cdc.gov/ mahc/editions/current.html). MAHC is national guidance that can be voluntarily adopted by state and local jurisdictions to minimize the risk for illness and injury at public aquatic facilities through facility design, construction, operation, maintenance, and management.

The 2016 MAHC reflects input from state and local public health colleagues, aquatics professionals, and other stakeholders who joined the Council for the Model Aquatic Health Code (CMAHC*; http://www.cmahc.org). CMAHC collects, assesses, and relays input on MAHC revisions to $\mathrm{CDC}$ for consideration.

In October 2015, the first CMAHC biennial conference was held to review 159 proposed MAHC revisions. During November 21-December 20, 2015, CMAHC members voted and approved 92 (58\%) revisions, including new or revised recommendations related to disinfection and water quality; lifeguarding and bather supervision; risk management and safety; and ventilation and air quality. In January 2016, the CMAHC director informed CDC of the voting results. The

\footnotetext{
*Information on how to become a CMAHC member is available at http:// www.cmahc.org/membership.php.
}

MAHC is updated every 2 years through this CMAHC-CDC revision process to ensure that the MAHC remains current and takes into account the latest scientific data and aquatics sector innovations.

An important change in the 2016 MAHC recommends that when hyperchlorinating to inactivate Cryptosporidium (the leading cause of aquatic facility-associated disease outbreaks) and in response to diarrheal incidents in the water (high-risk Cryptosporidium contamination events), concentrations of chlorine stabilizer ${ }^{\dagger}$ not exceed $15 \mathrm{ppm}$ (1). Previous recommendations for hyperchlorinating and responding to diarrheal incidents in the presence of chlorine stabilizer permitted cyanuric acid concentrations of up to $50 \mathrm{ppm}$ (2). Current CDC hyperchlorination and fecal incident response recommendations are aligned with the MAHC and are available at http:// www.cdc.gov/healthywater/swimming/aquatics-professionals/ fecalresponse.html.

$\bar{\dagger}$ Chlorine stabilizers include compounds such as cyanuric acid, dichlor, and trichlor.

\section{References}

1. Murphy JL, Arrowood MJ, Lu X, Hlavsa MC, Beach MJ, Hill VR. Effect of cyanuric acid on the inactivation of Cryptosporidium parvum under hyperchlorination conditions. Environ Sci Technol 2015;49:7348-55. http://dx.doi.org/10.1021/acs.est.5b00962

2. Shields JM, Arrowood MJ, Hill VR, Beach MJ. The effect of cyanuric acid on the disinfection rate of Cryptosporidium parvum in 20-ppm free chlorine. J Water Health 2009;7:109-14. http://dx.doi.org/10.2166/ wh.2009.008 